\title{
Tautomerism in Fuscin - A DFT Treatment
}

\section{Lemi Türker}

Department of Chemistry, Middle East Technical University, Üniversiteler, Eskişehir Yolu No: 1, 06800 Çankaya/Ankara, Turkey; e-mail: 1turker@gmail.com; 1turker@metu.edu.tr

\section{Abstract}

\begin{abstract}
Fuscin, a natural product having various functionalities, may exhibit 1,3- and 1,5-proton tautomerism, as well as valence tautomerism via its 1,5-proton tautomer. All those possible forms are investigated within the realm of density functional theory with the constraints of B3LYP/6-311+G(d,p) level. NICS(0) calculation has been performed for the valence tautomer which possesses a benzenoid ring. The tautomers are found to be stable structures but the valence tautomer is the least likely one. Some QSAR, quantum chemical and spectral properties are obtained and discussed.
\end{abstract}

\section{Introduction}

Fuscin is an orange-colored compound. Easily reduced by hydrosulfite or other reducing agents to the colorless dihydrofuscin, $\mathrm{C}_{15} \mathrm{H}_{18} \mathrm{O}_{5}$. Its systematic name is (4S)-5Hydroxy-4,8,8-trimethyl-9,10-dihydro-2H,4H-pyrano[4,3-f]chromene-2,6(8H)-dione. It is one of the dipyrrylmethene pigments [1]. In the literature studies on fuscin goes back to many decades ago. Barton and Hendrickson studied the constitution and synthesis of fuscin [2]. Fuscin and some analogous compounds exist in certain microorganisms [3-7].

Catabolism of fuscin was studied by Hammerbeck [8]. Fate of bilirubin depending upon conjugation and other factors including fuscin pigments was investigated by Gilbertsen and Watson [9].

In recent years the scientific interest on fuscin has been renewed due to anti-HIV properties of fuscin and other fuscin pigments [9-12]. Fuscin is known to compete Received: August 7, 2020; Accepted: September 9, 2020

Keywords and phrases: fuscin, tautomerism, density functional, HIV, valence tautomer.

Copyright (C) 2020 Lemi Türker. This is an open access article distributed under the Creative Commons Attribution License, which permits unrestricted use, distribution, and reproduction in any medium, provided the original work is properly cited. 
effectively with macrophage inflammatory protein (MIP)-1 $\alpha$ for binding to human CCR5, an important anti HIV target that interferes with HIV entry into cells. In addition, it shows inhibitory effect on respiration and oxidative phosphorylation in ox-neck muscle mitochondria.
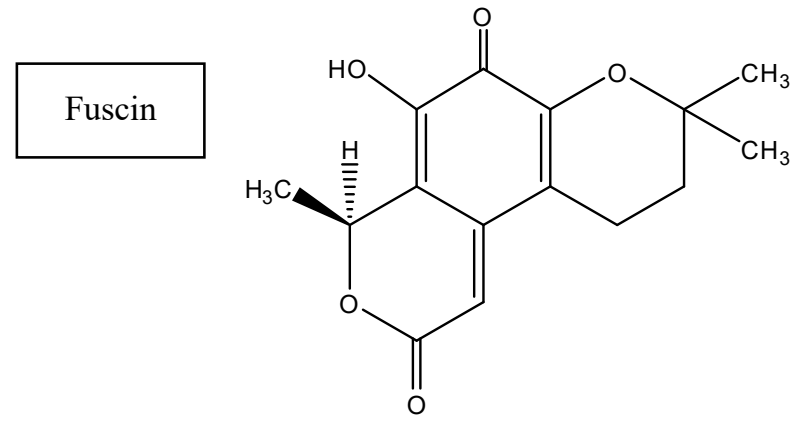

In the present study, various tautomers of fuscin are investigated quantum chemically within the restrictions of density functional theory (DFT).

\section{Method of Calculation}

In the present study, the initial structural optimizations of all the structures leading to energy minima have been achieved by using MM2 method followed by semi-empirical PM3 self-consistent fields molecular orbital (SCF MO) method $[13,14]$ at the restricted level $[15,16]$. Subsequent optimizations were achieved at Hartree-Fock level using various basis sets. Then, the structural optimizations were managed within the framework of density functional theory (DFT) $[17,18]$ at the level of B3LYP/6$311+\mathrm{G}(\mathrm{d}, \mathrm{p})[16,19]$. The exchange term of B3LYP consists of hybrid Hartree-Fock and local spin density (LSD) exchange functions with Becke's gradient correlation to LSD exchange $[18,20]$. The correlation term of B3LYP consists of the Vosko, Wilk, Nusair (VWN3) local correlation functional [21] and Lee, Yang, Parr (LYP) correlation correction functional [22]. Also, the vibrational analyses have been done. The total electronic energies are corrected for the zero point vibrational energy (ZPE). The normal mode analysis for each structure yielded no imaginary frequencies for the $3 N-6$ vibrational degrees of freedom, where $N$ is the number of atoms in the system. This indicates that the structure of each molecule corresponds to at least a local minimum on the potential energy surface. All these calculations were done by using the Spartan 06 package program [23].

For NICS data, the absolute NMR shielding values [24] were calculated by employing the Gauge-Independent Atomic Orbital method [25] with the restricted closed 
shell formalism at the level of B3LYP/6-311+G(d,p). The NICS values were collected by calculating absolute NMR shielding values at the ring centers, NICS (0). The NICS (0) calculations of the present systems were performed by the use of the Gaussian 03 package program [26].

\section{Results and Discussion}

Fuscin molecule (F0) possesses, pyran ring, a lactone moiety, and keto and enol groups. The presence of enol group may be responsible for a keto-enol tautomerism. Due to the structural organization of the carbon-carbon double bonds in its structure, not only 1,3-type $(\mathrm{F} 1,3)$ but also 1,5-type $(\mathrm{F} 1,5)$ proton tautomerisation is possible in fuscin molecule. More interesting probability is the valence tautomer (valence isomer) of 1,5tautomer of fuscin which should have a four membered cyclic peroxide system (FP).

Tautomers of the present concern are shown in Figure 1. Note that F1,3 and F1,5 are proton tautomers whereas FP is the valence tautomer of F1,5. It is noteworthy that FP contains an aromatic ring.

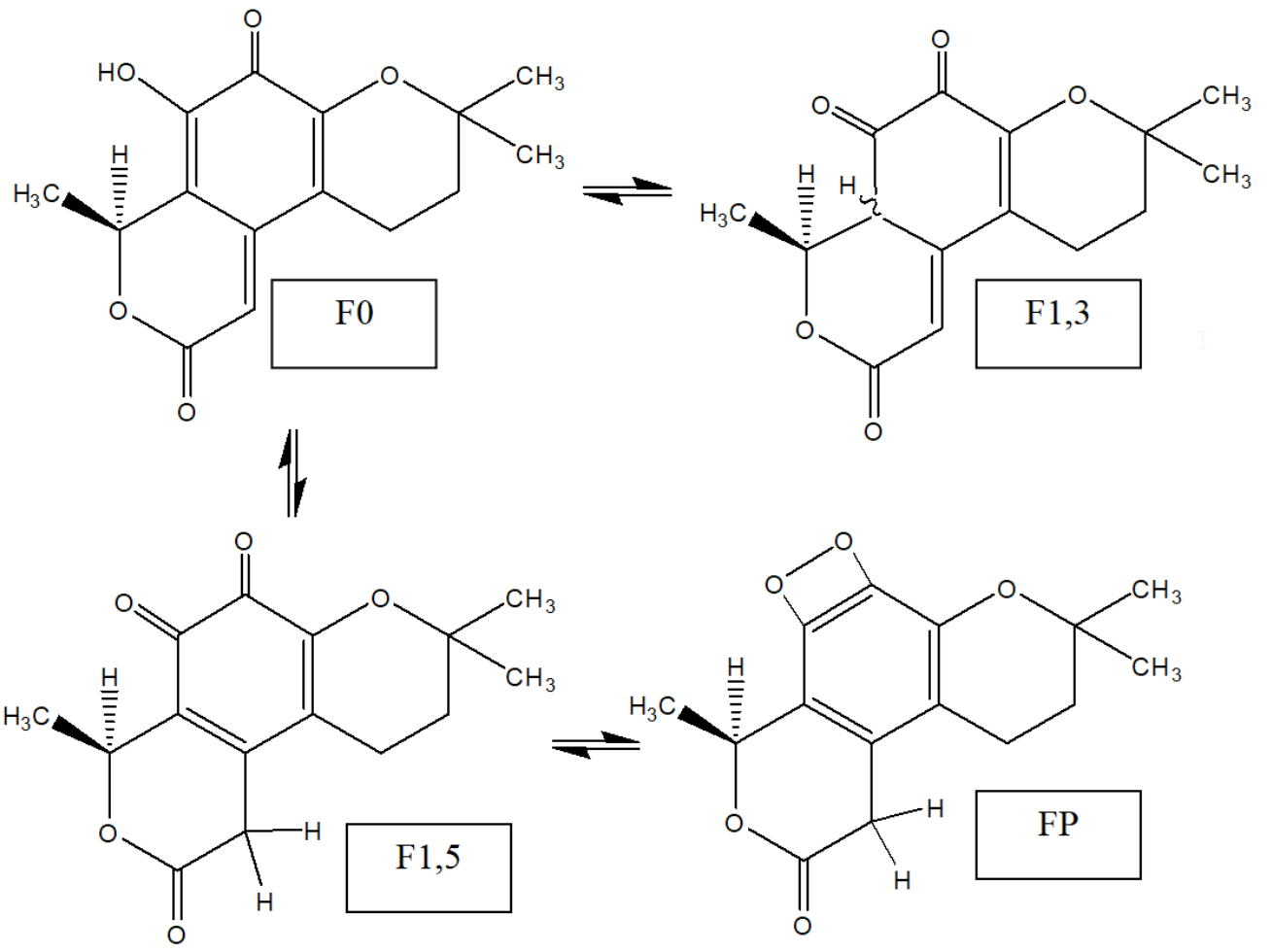

Figure 1. Tautomers of the present concern. 
Degenerate interconversions can be considered a special case of rearrangements called valence isomerization or valence tautomerisation [27-39]. A general scheme is proposed for the interconversions of six-membered oxygen-containing heterocycles (pyrylium salts, pyrans, and pyrones) and their open-chain forms, having selected pyrylium salts as compounds of the key type [39]. The latest data concerning the mechanism of a number of the above transformations are examined. It is shown that ring opening is one of the most characteristic manifestations of the reactivity of sixmembered oxygen-containing heterocycles [39].

The deriving force for the formation of valence tautomer (FP) could be the aromatization of the middle ring of F1,5. The performed $\mathrm{NICS}(0)$ calculations for benzene and FP ( a closed shell structure) indicate that FP is highly aromatic (benzene: -8.019, FP: -12.816).

Although 4-membered peroxide ring is expected to add some instability to the system, the accompanying aromatic ring formation should contribute to the stability of it. A plausible path for the conversion of F1,5 to FP is shown in Figure 2. Table 1 shows some properties of the tautomers considered where abbreviation FBR stands for the biradical specie shown in Figure 2.
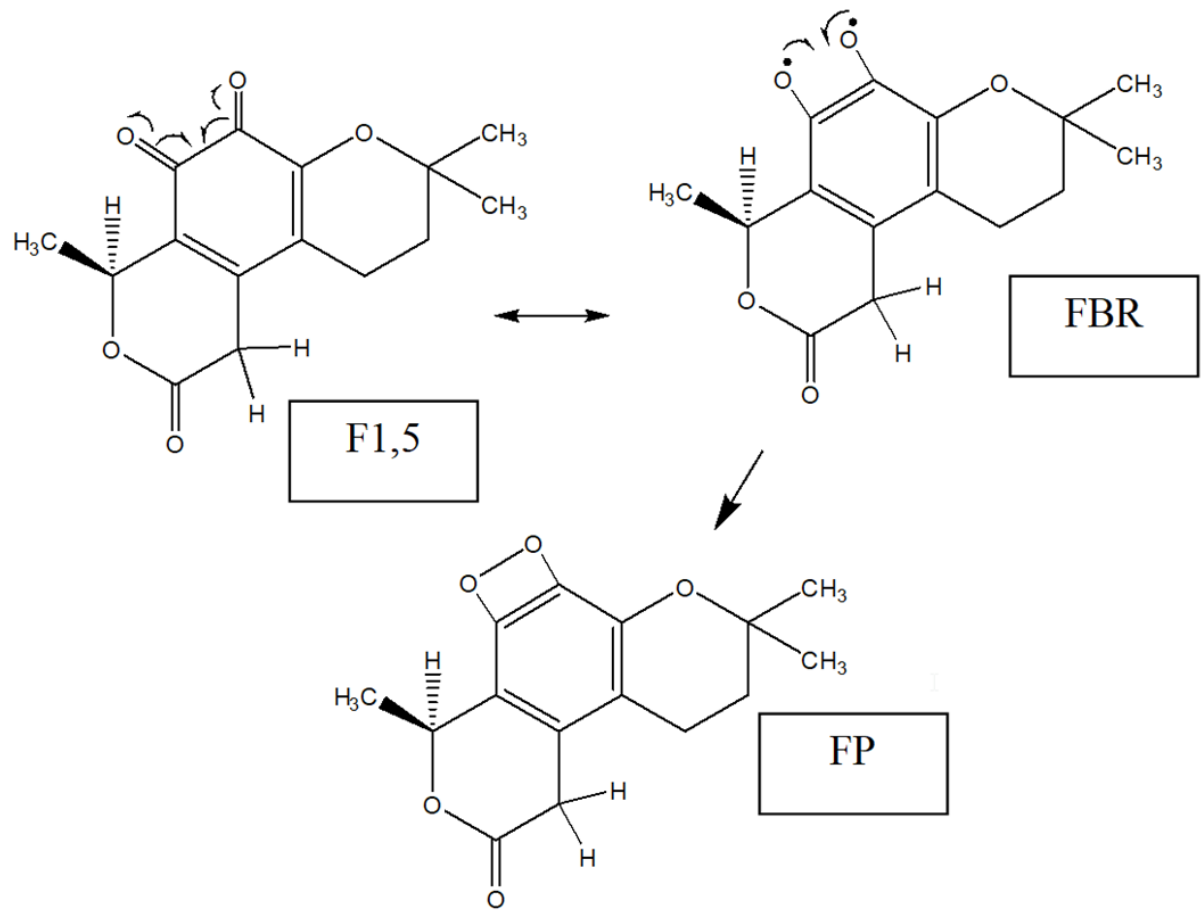

Figure 2. A plausible path for the conversion. 
Table 1. Some properties of the structures.

\begin{tabular}{lcccccc}
\hline Structure & $\begin{array}{c}\text { Area } \\
\AA^{2}\end{array}$ & $\begin{array}{c}\text { Volume } \\
\AA^{3}\end{array}$ & Ovality & $\begin{array}{c}\text { Dipole } \\
\text { moment }\end{array}$ & Log P & Polarizability \\
\hline F0 & 280.28 & 267.48 & 1.40 & 5.41 & -0.39 & 62.27 \\
F1,3 & 279.92 & 267.84 & 1.39 & 6.02 & 0.80 & 62.24 \\
F1,5 & 281.33 & 268.22 & 1.40 & 6.95 & 0.41 & 62.46 \\
FP & 277.98 & 266.08 & 1.39 & 5.33 & -1.65 & 61.90 \\
\hline
\end{tabular}

Dipole moment in debye units.

Figure 3 shows the optimized structures of the tautomers as well as the directions of the dipole moment vectors. In all the structures, the dipole moment vector originates from somewhere on the dimethyl substituted pyran ring.
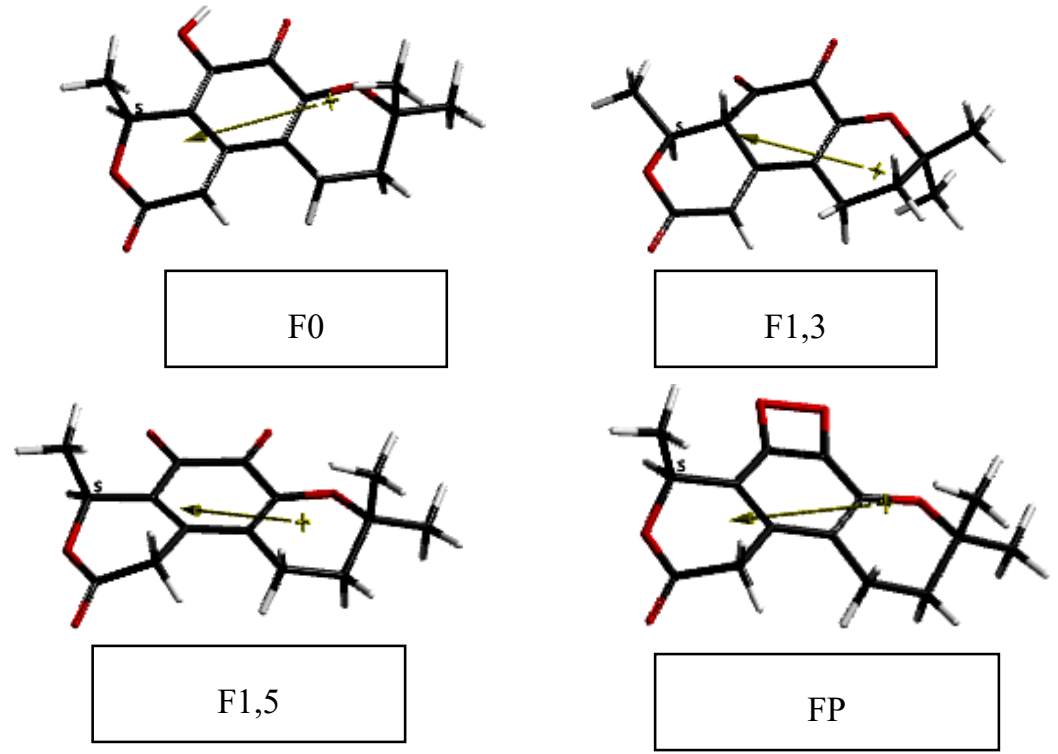

Figure 3. Optimized structures of the molecules considered. $6-311+\mathrm{G}(\mathrm{d}, \mathrm{p})$.

Figure 4 shows the electrostatic potential charges (ESP) on the atoms of the structures. Note that the ESP charges are obtained by the program based on a numerical method that generates charges that reproduce the electrostatic potential field from the entire wavefunction [23]. 

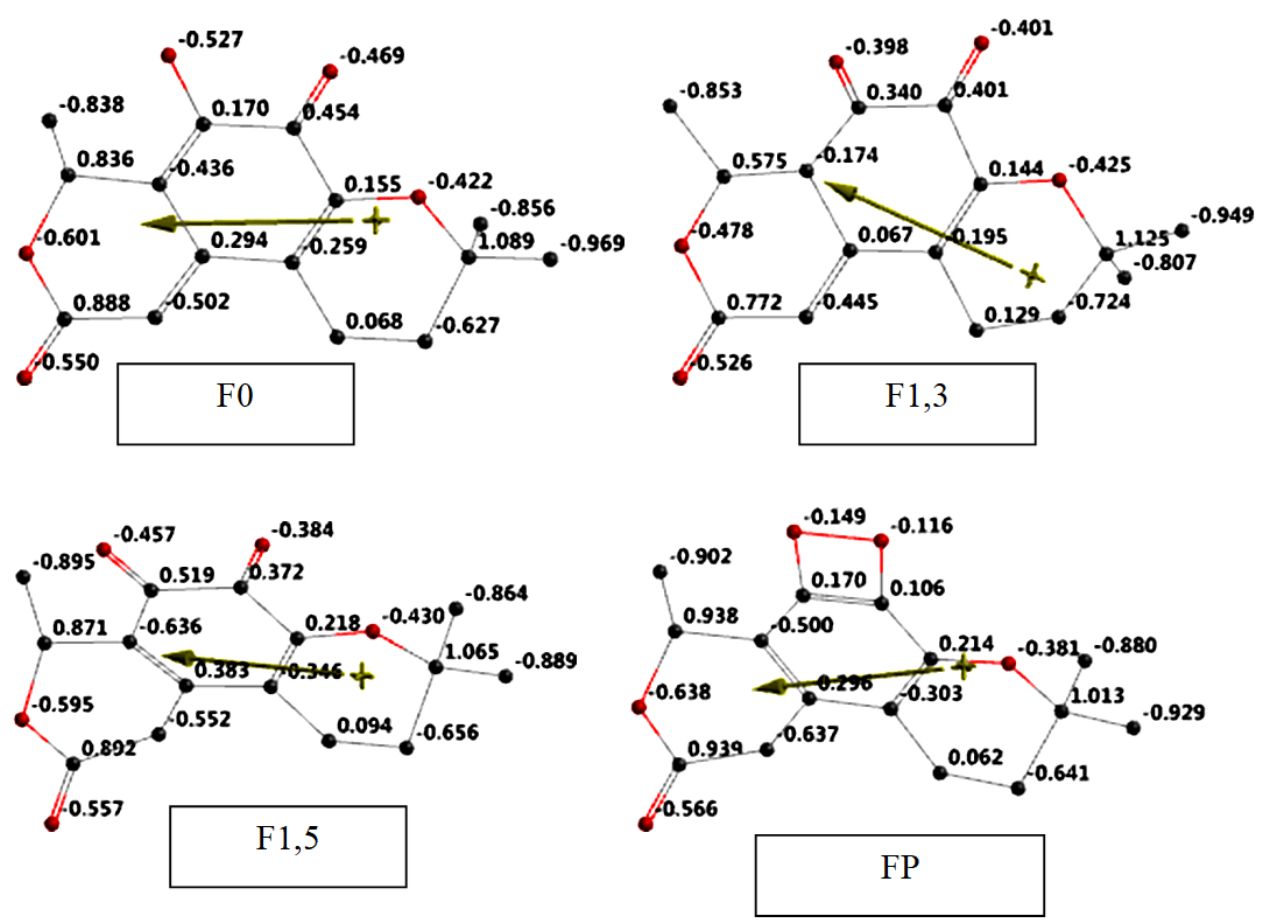

Figure 4. The ESP charges on atoms of the structures considered (Hydrogens not shown).

Figure 5 shows the electrostatic potential maps of the tautomers considered. Note that in the figure red and blue regions stand for electronegative and electropositive potential regions, respectively. As seen in the figure the lactone moiety is red in all the tautomers. The bluish region in F1,3 is concentrated on the proton shifted whereas in F1,5 it is highly spread over the backbone. The red/reddish regions stand for proton acceptor sites suitable for hydrogen bond formations.

Table 2 displays some energies of the structures considered where E, ZPE and $\mathrm{E}_{\mathrm{C}}$ stand for the total electronic energy, zero point vibrational energy and the corrected total electronic energy respectively. 

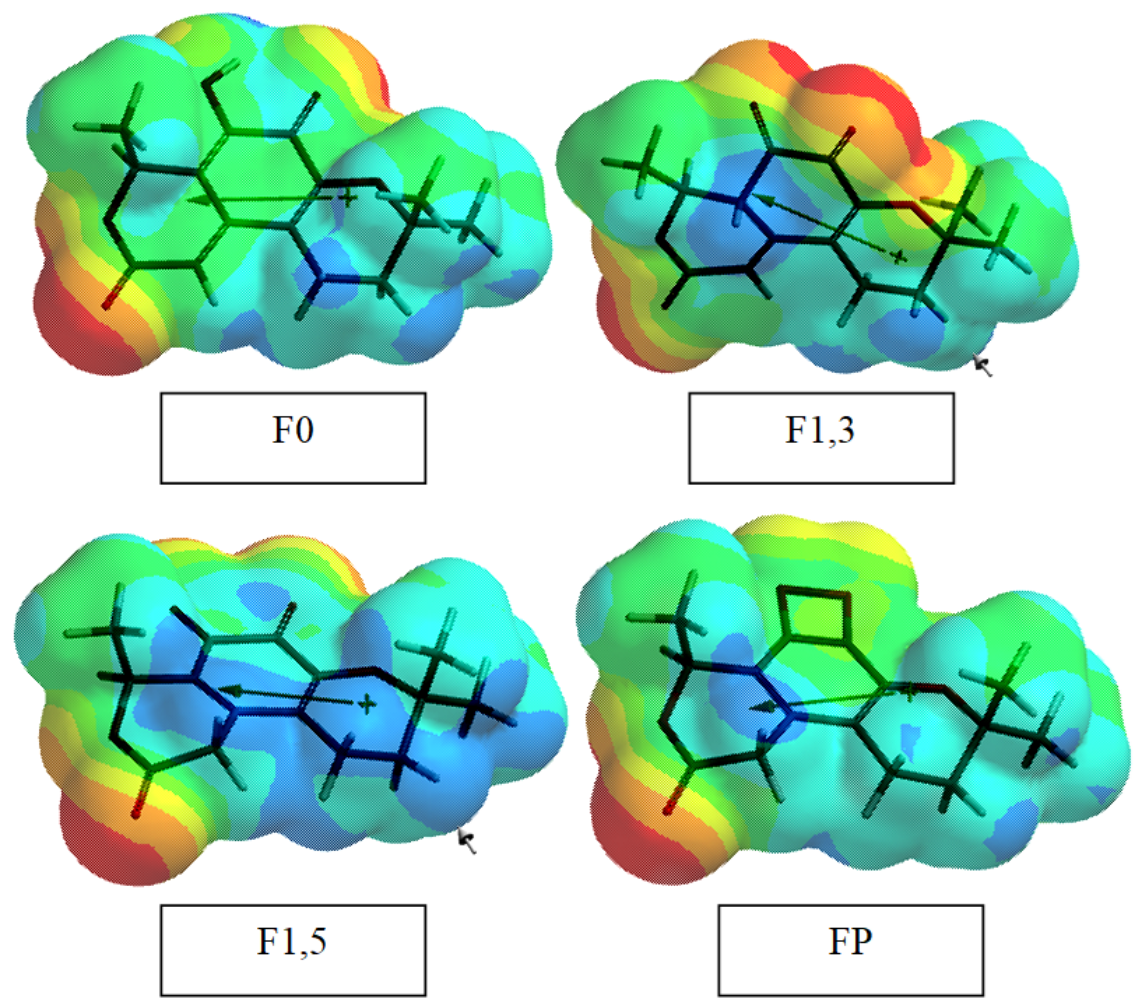

Figure 5. Electrostatic potential maps of the structures considered.

Table 2. Some energies of the isomeric structures.

\begin{tabular}{lccc}
\hline Structure & $\mathbf{E}$ & $\mathbf{Z P E}$ & $\mathbf{E}_{\mathbf{C}}$ \\
\hline F0 & -2514228.92 & 754.41 & -2513474.51 \\
F1,3 & -2514180.88 & 753.41 & -2513427.47 \\
F1,5 & -2514174.76 & 751.99 & -2513422.77 \\
FP & -2513854.00 & 753.66 & -2513100.34 \\
\hline
\end{tabular}

Energies in $\mathrm{kJ} / \mathrm{mol}$. 6-311+G(d,p).

According to $\mathrm{E}_{\mathrm{C}}$ values, fuscin is the electronically most stable isomer among the all. The stability order is $\mathrm{F} 0>\mathrm{F} 1,3>\mathrm{F} 1,5>\mathrm{FP}$.

Table 3 shows some thermodynamic properties of the structures considered. The data reveal that they are all exothermic structures having positive entropy values. The order of 
heat of formation values is $\mathrm{F} 0<\mathrm{F} 1,3<\mathrm{F} 1,5<\mathrm{FP}$. A similar trend is obtained for the Gibbs free energy of formation values, hence fuscin is the most likely whereas the peroxide (FP) is the least likely isomer. Although, the peroxide contains an aromatic ring, the 4-membered ring should add an appreciable amount of ring strain beside the lone pair-lone pair repulsion energy originating from the peroxide oxygens.

Table 3. Some thermodynamic properties of the structures.

\begin{tabular}{lccc}
\hline Structure & $\mathbf{H}$ & $\mathbf{S}^{\mathrm{o}}\left(\mathrm{J} / \mathrm{mol}^{\mathrm{o}}\right)$ & $\mathbf{G}^{\mathbf{o}}$ \\
\hline F0 & -2513454.11 & 510.15 & -2513606.21 \\
F1,3 & -2513407.10 & 509.24 & -2513558.93 \\
F1,5 & -2513402.18 & 511.33 & -2513554.63 \\
FP & -2513080.52 & 506.04 & -2513231.40 \\
\hline
\end{tabular}

Energies in $\mathrm{kJ} / \mathrm{mol}$.

Table 4 shows the HOMO, LUMO energies and the interfrontier molecular orbital energy gap $(\Delta \boldsymbol{\varepsilon})$ values of the structures considered. The order of HOMO energies is $\mathrm{F} 1,3<\mathrm{F} 0<\mathrm{F} 1,5<\mathrm{FP}$. The LUMO energy order is the sequence of $\mathrm{F} 1,5<\mathrm{F} 0<$ $\mathrm{F} 1,3<\mathrm{FP}$. As the result of those orders $\Delta \varepsilon$ values display the order of $\mathrm{FP}>\mathrm{F} 1,3>\mathrm{F} 0>\mathrm{F} 1,5$. The electronic variations as a result of tautomeric structural changes lower the HOMO energy of fuscin in F1,3 but raises in F1,5, whereas the LUMO energy of F0 is raised in F1,3 but lowered in F1,5.

Table 4. The HOMO, LUMO energies and $\Delta \varepsilon$ values of the structures.

\begin{tabular}{lccc}
\hline Structure & HOMO & LUMO & $\Delta \varepsilon$ \\
\hline F0 & -660.00 & -334.32 & 325.68 \\
F1,3 & -669.26 & -318.96 & 350.30 \\
F1,5 & -643.91 & -368.15 & 275.76 \\
FP & -627.01 & -194.61 & 432.40 \\
\hline
\end{tabular}

Energies in $\mathrm{kJ} / \mathrm{mol}$.

Figure 6 shows some of the molecular orbital energy levels of the structures considered. Fuscin has almost degenerate HOMO and NHOMO (HOMO-1, 
NEXTHOMO) energy level. On the other hand, F1,3 and FP are characterized with comparatively narrower LUMO and NLUMO (LUMO+1, NEXTLUMO) referring to F0 and FP.
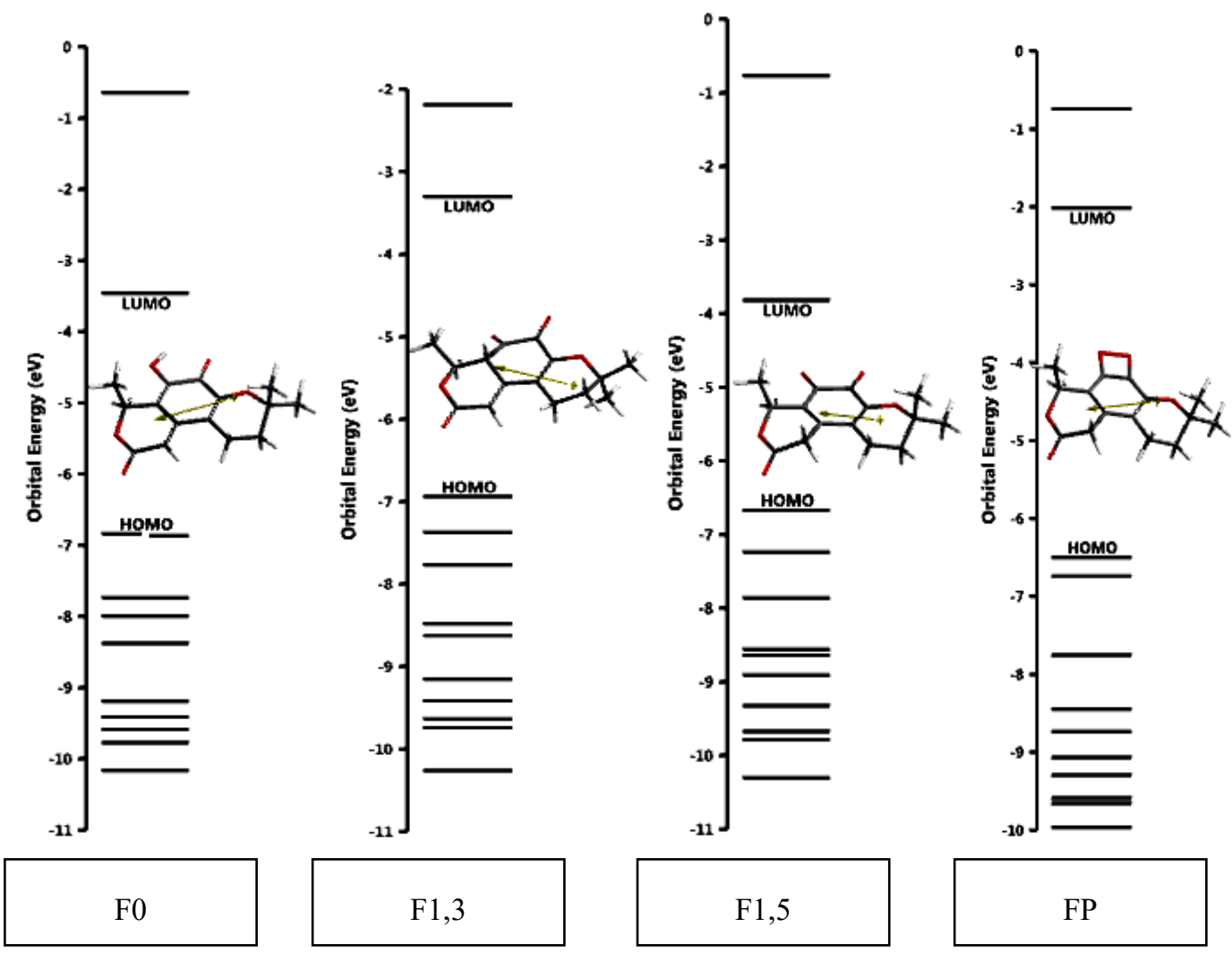

Figure 6. Some of the molecular orbital energy levels of the structures considered.

Figure 7 shows the time-dependent density functional (TDDFT) UV-VIS spectra of the structures considered. As going from F0 to F1,5, the spectra exhibit shift to visible region (bathochromic effect), meantime intensity of the peaks in the visible part increases. In addition to that the spectrum of F1,5 has two $\lambda_{\max }$ values in the visible region. It is due to the presence of two enone chromophore systems and the increased conjugation as compared to F0 and F1,3.

Figure 8 shows the local ionization potential maps of the structures considered. In a local ionization potential map conventionally red regions on the density surface indicate areas from which electron removal is relatively easy, meaning that they are subject to electrophilic attack. On the other hand, regions having blue color represent areas where 
ionization is relatively difficult. Hence, 1,5-tautomer having higher HOMO energy level than fuscin should be relatively more susceptible to electron donation.
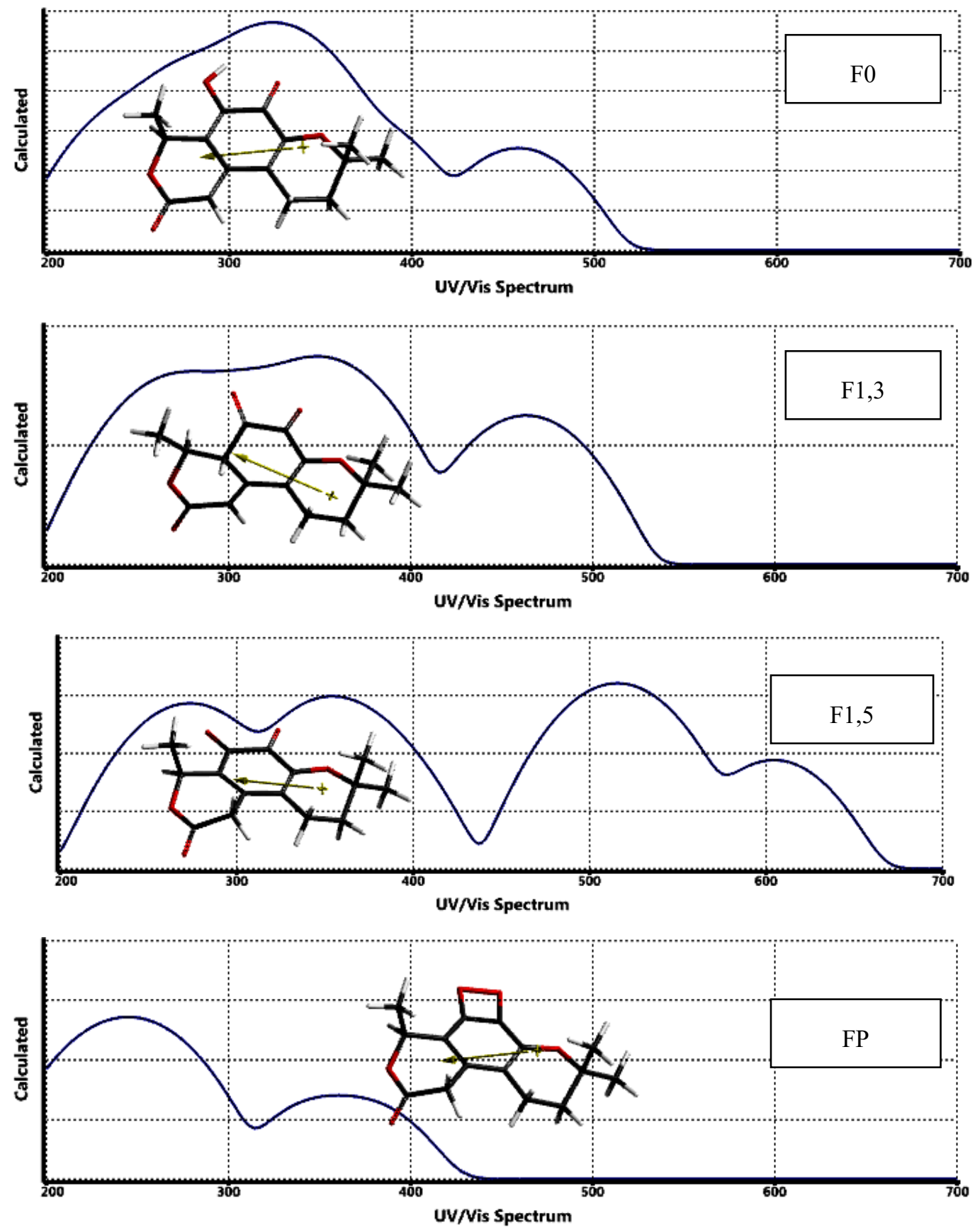

Figure 7. UV-VIS spectra (TDDFT) of the structure considered. 

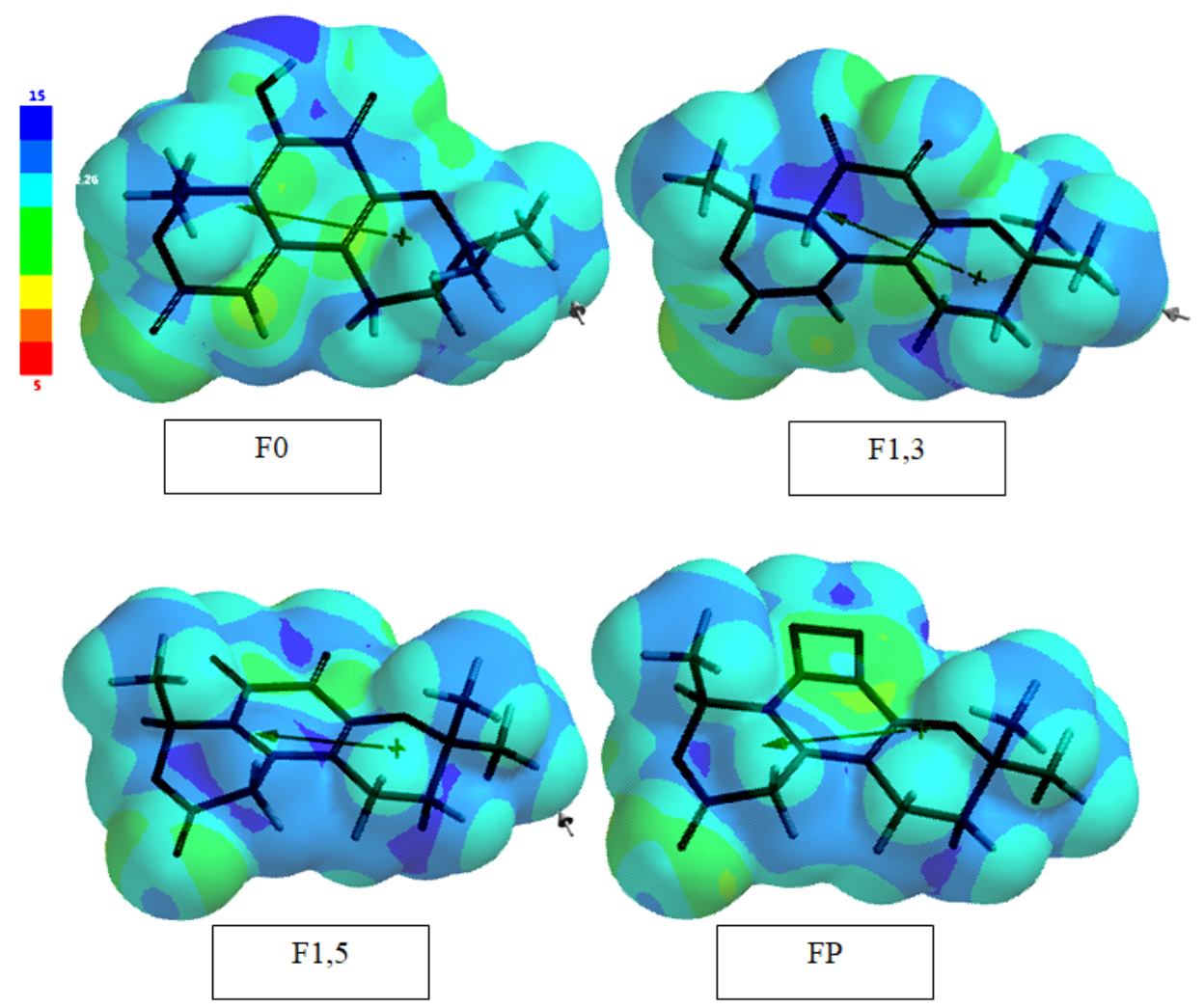

Figure 8. The local ionization potential maps of the structures considered.

Figure 9 shows the LUMO maps of the structures considered. A LUMO map displays the absolute value of the LUMO on the electron density surface. The blue color stands for the maximum value of the LUMO and the color red, the minimum value. Hence, a nucleophile attacks on the atom having the blue/bluish color [23]. Hence, the 1,5-tautomer having lower LUMO energy level than fuscin is expected to be more susceptible to nucleophilic attack. In those systems the regions of nucleophilic attack coincides with carbonyl groups. The disappearance of $\mathrm{C}=\mathrm{C}$ bond of fuscin, conjugated with the lactone moiety, caused that part of the system in the 1,5 tautomer red (see Figure 9) thus makes the lactone carbonyl out of consideration whereas in fuscin conjugate addition to lactone carbonyl is also possible. 

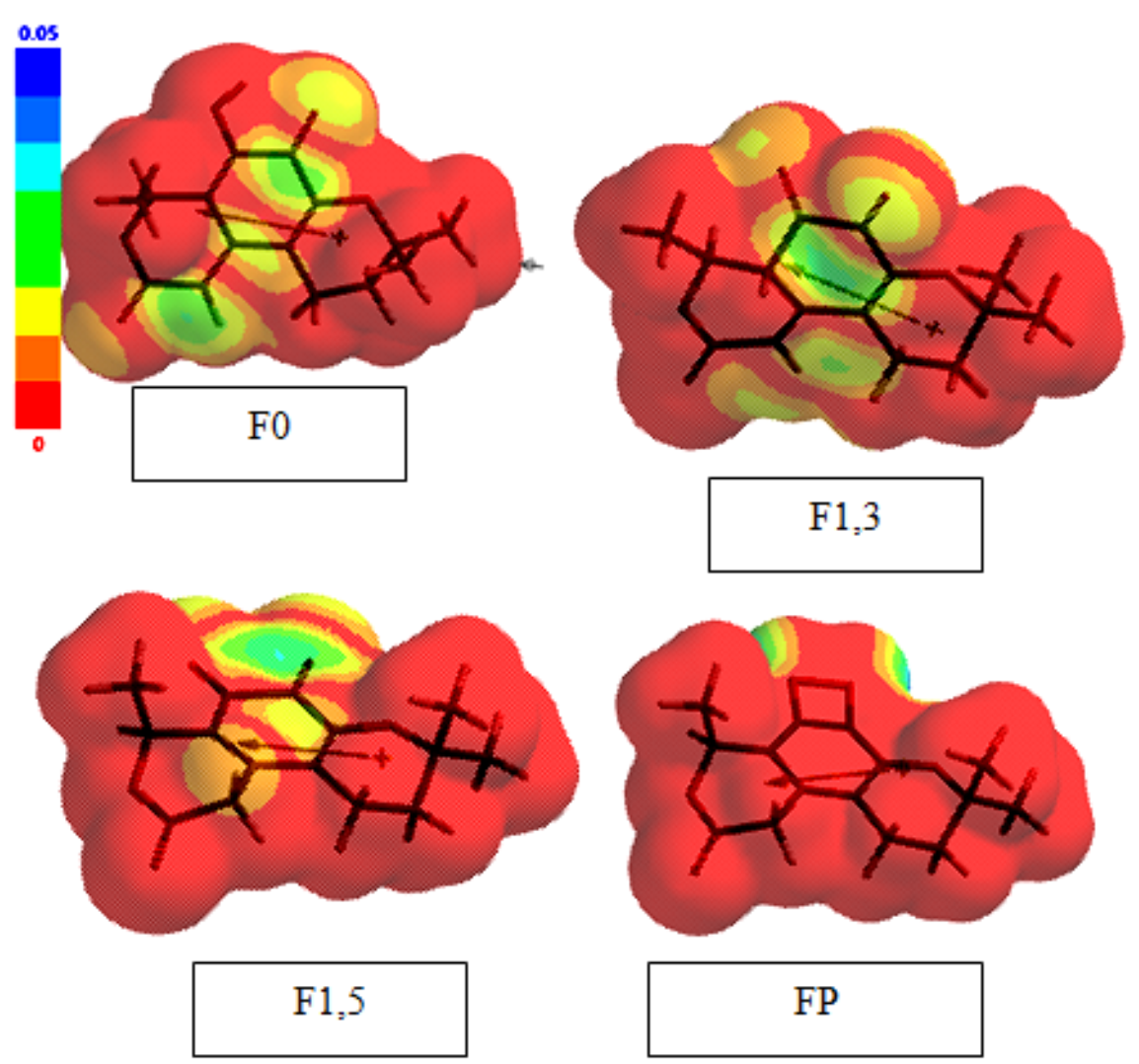

Figure 9. The LUMO maps of the structures considered.

Yoganathan et al. [12] reported HIV entry inhibitory activity of two new compounds, 10-methoxydihydrofuscin and fuscinarin, and a known fungal metabolite fuscin, isolated from the soil-derived mitosporic fungus Oidiodendron griseum. The greater activity of fuscin with respect to methoxydihydrofuscin and fuscinarin may be attributed to the presence of multiple reactive sites of the isochromene-5,9-dione unit in fuscin. Fuscin may exhibit proton tautomerism as indicated above whereas in 10-methoxydihydrofuscin and fuscinarin tautomerism should destroy the aromatic sextet of the middle ring. Thus, the tautomerism is not favored in those compounds. Note that the tautomerism increases the number of reactive sites too. Also, it highly affects the partition of the substance in aqueous and lipid phases. Hence, the greater activity of fuscin respect to the others mentioned above is expected. The tautomers F1,3 and F1,5 energetically following fuscin should also contribute the overall HIV entry inhibitory activity of fuscin. 

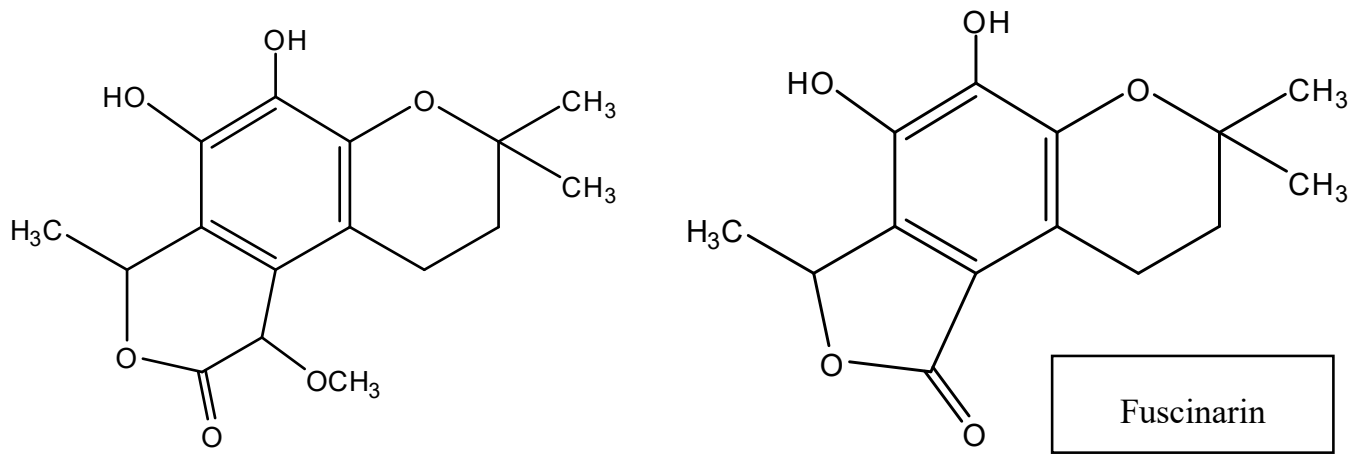

10-Methoxydihydrofuscin

\section{Conclusion}

Within the restrictions of density functional theory at the performed level of calculations, fuscin and its tautomers have been investigated in vacuum conditions. They are all stable and favorable but among the all, fuscin is the most and the valence tautomer is the least stable one, although the later one possesses an aromatic ring. Fuscin and its proton tautomers absorb both in UV and visible regions but the 1,5 tautomer exhibits remarkable bathochromic shift. The 1,5-proton tautomer having higher HOMO but lower LUMO energy levels as compared to fuscin is expected to be more susceptible to electrophilic and nucleophilic attacks than fuscin on the relative bases which might highly contribute the overall biological affects of fuscin.

\section{References}

[1] A.S. Gilbertsen, P.T. Lowry, V. Hawkinson and C.J. Watson, Studies of the dipyrrylmethene ("fuscin") pigments. I. The anabolic significance of the fecal mesobilifuscin, J. Clin. Invest. 38(7) (1959), 1166-1174. https://doi.org/10.1172/JCI103892

[2] D.H.R. Barton and J.B. Hendrickson, The constitution and synthesis of fuscin, J. Chem. Soc. (1956), 1028-1034. https://doi.org/10.1039/jr9560001028

[3] S.E. Michael, Studies in the biochemistry of micro-organisms 79. Fuscin, a metabolic product of Oidiodendron fuscum Robak. Part 1. Preparation, properties and antibacterial activity, Biochem. J. 43 (1948), 528-533. https://doi.org/10.1042/bj0430528 
[4] M. Navarri, C. Jégou, A. Bondon, S. Pottier, S. Bach, B. Baratte, S. Ruchaud, G. Barbier, G. Burgaud, and Y. Fleury, Bioactive metabolites from the deep subseafloor Fungus Oidiodendron Griseum UBOCC-A-114129, Mar Drugs. 15(4) (2017), 111. https://doi.org/10.3390/md15040111

[5] S.L. Morris, R.C. Walsh, and J.N. Hansen, Identification and characterization of some bacterial membrane sulfhydryl groups which are targets of bacteriostatic and antibiotic action, The Journal of Biological Chemistry 259 (21) (1984), 13590-13594.

[6] P.W. Brian, Antibiotics produced by fungi, Bot. Rev. 17 (1951), 357-430. https://doi.org/10.1007/BF02879038

[7] N.R. Andersen, H.O.B. Lorck and P.R. Rasmussen, Fermentation, isolation and characterization of antibiotic Pr-1350, The Journal of Antibiotics 36(7) (1983), 753-760. https://doi.org/10.7164/antibiotics.36.753

[8] W. Hammerbeck, Fuscin granules (catabolism granules) in the human myocardium, Zentralblatt fur Allgemeine Pathologie u. Pathologische Anatomie 100 (1960), 305-324.

[9] A.S. Gilbertsen and C.J. Watson, Studies of the dipyrrylmethene ("Fuscin") Pigments. III. The variable fate of bilirubin depending upon conjugation and other factors, J. Clin. Invest. 41(5) (1962), 1041-1049. https://doi.org/10.1172/Jc1104554

[10] P. D. Yin, D. Das and H. Mitsuya, Overcoming HIV drug resistance through rational drug design based on molecular, biochemical, and structural profiles of HIV resistance, Cell. Mol. Life Sci. 63 (2006), 1706. https://doi.org/10.1007/s00018-006-6009-7

[11] B.G. Roy, Potential of small-molecule fungal metabolites in antiviral chemotherapy, Antiviral Chem. Chemother. 25(2) (2017), 20-52. https://doi.org/10.1177/2040206617705500

[12] K. Yoganathan, C. Rossant, S. Ng, Y. Huang, M.S. Butler and A.D. Buss, 10Methoxydihydrofuscin, fuscinarin, and fuscin, novel antagonists of the human CCR5 receptor from Oidiodendron griseum, J. Nat. Prod. 66(8) (2003), 1116-1117. https://doi.org/10.1021/np030146m

[13] J.J.P. Stewart, Optimization of parameters for semi empirical methods I. Method, $J$. Comput. Chem. 10 (1989), 209-220. https://doi.org/10.1002/jcc.540100208

[14] J.J.P. Stewart, Optimization of parameters for semi empirical methods II. Application, $J$. Comput. Chem. 10 (1989), 221-264. https://doi.org/10.1002/jcc.540100209

[15] A.R. Leach, Molecular Modeling, Essex: Longman, 1997.

[16] P. Fletcher, Practical Methods of Optimization, New York: Wiley, 1990. 
[17] W. Kohn and L. Sham, Self-consistent equations including exchange and correlation effects, J. Phys. Rev. 140 (1965), 1133-1138. https://doi.org/10.1103/PhysRev.140.A1133

[18] R.G. Parr and W. Yang, Density Functional Theory of Atoms and Molecules, London: Oxford University Press, 1989.

[19] C.J. Cramer, Essentials of Computational Chemistry, Chichester, West Sussex: Wiley, 2004.

[20] A.D. Becke, Density-functional exchange-energy approximation with correct asymptotic behavior, Phys. Rev. A 38 (1988), 3098-3100. https://doi.org/10.1103/PhysRevA.38.3098

[21] S.H. Vosko, L. Wilk and M. Nusair, Accurate spin-dependent electron liquid correlation energies for local spin density calculations: a critical analysis, Can. J. Phys. 58 (1980), 1200-1211. https://doi.org/10.1139/p80-159

[22] C. Lee, W. Yang and R.G. Parr, Development of the Colle-Salvetti correlation-energy formula into a functional of the electron density, Phys. Rev. B 37 (1988), 785-789. https://doi.org/10.1103/PhysRevB.37.785

[23] SPARTAN 06, Wavefunction Inc., Irvine CA, USA, 2006.

[24] P. Pulay, J. F. Hinton and K. Wolinski, Efficient implementation of the GIAO method for magnetic properties: theory and application. In: Tossell J.A. (eds.) Nuclear Magnetic Shieldings and Molecular Structure, NATO ASI Series (Series C: Mathematical and Physical Sciences), vol. 386, pp. 243-262, Springer, Dordrecht, 1993. https://doi.org/10.1007/978-94-011-1652-7_12

[25] W.J. Hehre, L. Radom, P.R. van Schleyer and J.A. Pople, Ab Initio Molecular Orbital Theory, New York: Wiley, 1986.

[26] M.J. Frisch, G.W. Trucks, H.B. Schlegel, G.E. Scuseria, M.A. Robb, J.R. Cheeseman, J.A. Montgomery, Jr., T. Vreven, K.N. Kudin, J.C. Burant, J. M. Millam, S. S. Iyengar, J. Tomasi, V. Barone, B. Mennucci, M. Cossi, G. Scalmani, N. Rega, G.A. Petersson, H. Nakatsuji, M. Hada, M. Ehara, K. Toyota, R. Fukuda, J. Hasegawa, M. Ishida, T. Nakajima, Y. Honda, O. Kitao, H. Nakai, M. Klene, X. Li, J. E. Knox, H. P. Hratchian, J. B. Cross, V. Bakken, C. Adamo, J. Jaramillo, R. Gomperts, R.E. Stratmann, O. Yazyev, A.J. Austin, R. Cammi, C. Pomelli, J.W. Ochterski, P.Y. Ayala, K. Morokuma, G.A. Voth, P. Salvador, J.J. Dannenberg, V.G. Zakrzewski, S. Dapprich, A.D. Daniels, M.C. Strain, O. Farkas, D.K. Malick, A.D. Rabuck, K. Raghavachari, J.B. Foresman, J.V. Ortiz, Q. Cui, A.G. Baboul, S. Clifford, J. Cioslowski, B.B. Stefanov, G. Liu, A. Liashenko, P. Piskorz, I. Komaromi, R.L. Martin, D.J. Fox, T. Keith, M.A. Al-Laham, 
C.Y. Peng, A. Nanayakkara, M. Challacombe, P.M. W. Gill, B. Johnson, W. Chen, M.W. Wong, C. Gonzalez and J.A. Pople, Gaussian, Inc., Wallingford CT, 2004.

[27] O. Reutov, Theoretical Principles of Organic Chemistry, Moscow: Mir Pub, 1970.

[28] E.V. Anslyn and DA. Dougherty, Modern Physical Organic Chemistry, Sausalito, California: University Science Books, 2006.

[29] S. Sarel and J. Rivlin, Ring-chain valence tautomerism in chlorinated 2H-pyran systems, Tetrahedron Lett. 6(13) (1965), 821-828.

https://doi.org/10.1016/S0040-4039(00)90025-X

[30] C.D. Gabbutt, B.M. Heron, S.B. Kolla, C. Kilner, S.J. Coles, P.N. Horton and M.B. Hursthouse, Ring contraction during the $6 \pi$-electrocyclisation of naphthopyran valence tautomers, Org. Biomol. Chem. 6(17) (2008), 3096-3104.

https://doi.org/10.1039/B807744D

[31] C.M. Moorhoff, New annulation techniques; condensations of phosphonium ylides and substituted 2H-pyran-5-carboxylates; preparation of cyclohexenonedicarboxylates and cyclohexadienedicarboxylates, J. Chin. Chem. Soc. 50 (2003), 419-424.

https://doi.org/10.1002/jccs.200300064

[32] L.R. Smith, Schemes and transformation in $(\mathrm{CH}) 8$ series, The "valence isomers" of cyclooctatetraene, J. Chem. Ed. 55(9) (1978), 569-576.

https://doi.org/10.1021/ed055p569

[33] D. Tejedor, S. Delgado-Hernández, R. Diana-Rivero, A. Díaz-Díaz and F. GarcíaTellado, Recent advances in the synthesis of 2H-pyrans, Molecules 24 (2019), 29042920. https://doi.org/10.3390/molecules.24162904

[34] J.D. Hepworth and B.M. Heron, Synthesis and photochromic properties of naphthopyrans, In Progress in Heterocyclic Chemistry; G.W. Gribble, J.A. Joule, (Eds.) vol. 17, pp. 33-62, Oxford (UK): Elsevier, 2005.

https://doi.org/10.1016/S0959-6380(05)80324-1

[35] E. Vogel, Valence isomerizations in compounds with strained rings, Angew. Chem. Int. Ed. Engl. 2 (1963), 1-11. https://doi.org/10.1002/anie.196300011

[36] E.N. Marvell, G. Caple, T.A. Gosink and G. Zimmer, Valence isomerization of a cisdienone to an $\alpha$-pyran, J. Am. Chem. Soc. 88 (1966), 619-620. https://doi.org/10.1021/ja00955a050

[37] E.N. Marvell and T.A. Gosink, Valence isomerization of 2,4,6-trimethyl-2H-pyran, $J$. Org. Chem. 37 (1972), 3036-3037. https://doi.org/10.1021/jo00984a030 
[38] T.A. Gosink, Valence isomers. Substituent effects on the equilibrium between 2H-pyrans and cis dienones, J. Org. Chem. 39 (1974), 1942-1943. https://doi.org/10.1021/jo00927a032

[39] O.V. Drygina, A.D. Garnovskii and A.V. Kazantsev, The interconversions of pyrylium salts, pyrans, pyrones, and their open-chain forms, Russ. Chem. Rev. 54(12) (1985), 11671184. https://doi.org/10.1070/RC1985v054n12ABEH003163 